\title{
lonosphere modification and topology of ionospheric magnetically-oriented irregularities
}

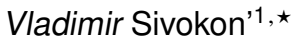 \\ ${ }^{1}$ Institute of Cosmophysical Research and Radio Wave Propagation FEB RAS, Kamchatskiy kray, Paratunka, \\ Russia
}

\begin{abstract}
One of the perspective directions of active impact on the ionosphere is the formation of electron concentration irregularities. Such irregularities can be used to increase the efficiency of radar systems and signal transfer in an interlayer ionospheric waveguide. Experiments on Alaska-Antarctica path showed that signal level at a receiving site is determined by heating wave parameters. In this case we did not study the character of its level change with time, i.e. possible fading, that is very important for radio-engineering systems. It is known that fading is determined by dimensions and space distribution of irregularity. Observations over EISCAT experiments make it possible, to some degree, to show the character of a scattered signal and the topology of ionospheric magneticallyoriented irregularities in the area of active impact on the ionosphere.
\end{abstract}

\section{Introduction}

Some patents [1-3] are known which suggest applying ionospheric artificial irregularities to increase the efficiency of radio-engineering systems. The researchers from USA and Khar'kov Institute of Radio Astronomy carried out such experiments in 2014 [4]. Ionospheric electron concentration irregularities were formed in Alaska by HAARP heating stand. By the means of artificial radio-wave radiation of the ionosphere, signal is injected into an ionospheric waveguide channel. Signal was received at Vernadskiy observatory in Antarctica. The experiments showed signal intensity variations during heating wave frequency change, however, it is impossible to estimate signal change in time from the published data that is very important for effective functioning of radio-engineering systems.

Analysis of the signals, which we recorded from the Arecibo heating stand during the experiments on generation of artificial magnetically-oriented irregularities, showed significant amplitude fluctuations. That makes the investigation of the character of signals scattered on ionospheric artificial irregularities topical.

To investigate the properties of ionospheric artificial irregularities, we apply SDR (Soft Defined Radio) networks. One of the requirements determining the choice of a receiver is its location in the line of sight of the impact area. That allows us to exclude the effect of propagation conditions on observation results. First observations over the EISCAT program experiments made it possible to obtain

\footnotetext{
${ }^{\star}$ Corresponding author: sivokon.vladimir@yandex.ru;

The paper was carried out within the framework on the subject «Dynamics of physical processes in active zones of near space and geospheres» (AAAA-A17-117080110043-4)
} 
the experience to work with such receivers and to determine an optimum mode for demodulation and recording of heating emission [5].

\section{Method justification}

Mechanism of ionospheric waveguide excitation, as experimentators represent it [4], is illustrated in (Fig.1). It is clear from the figure that the basis of it is a cone scattering model. However, experimental data analysis does not completely agree with the model. For example, energy main flow in the model is concentrated in the scattering cone and only a small portion of it gets into ionospheric waveguide. Heating emission frequency change in the experiment caused signal intensity change at the receiving point. As long as cone scattering is only possible under the condition that irregularity longitudinal dimensions are much more than the wave length, it is unlikely that frequency insignificant change, 5,65 - 5,95 MHz, heating wave frequency change, would cause significant change of received signal amplitude observed in the experiment.

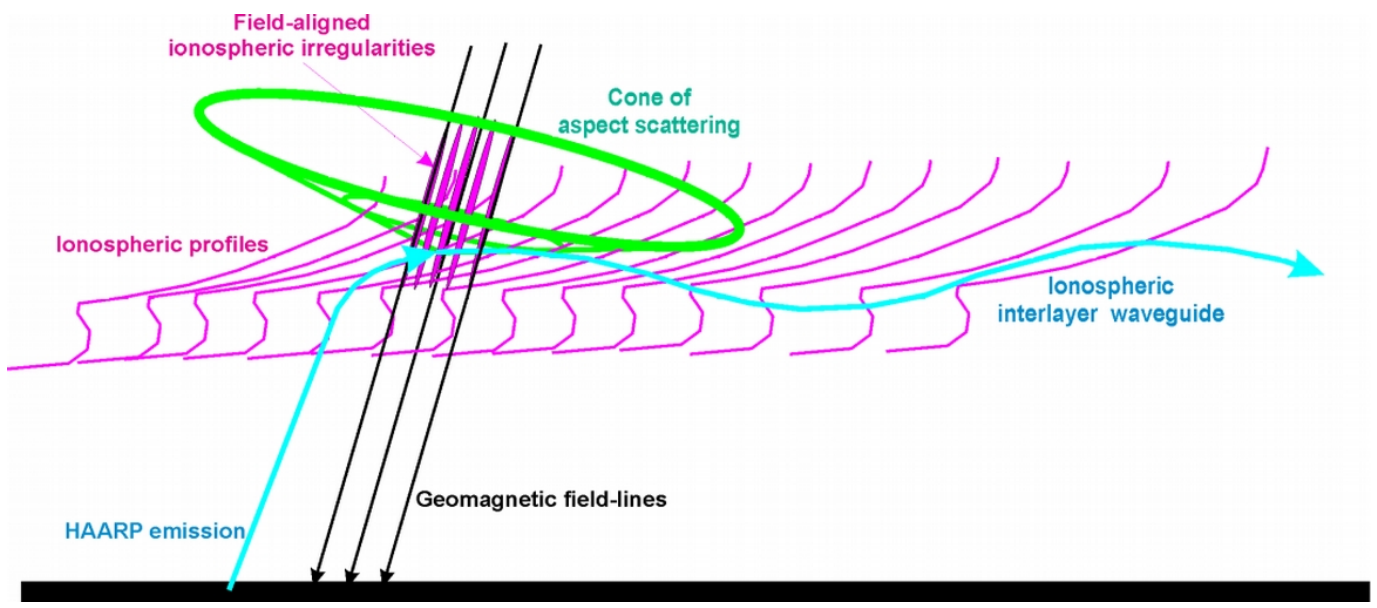

Figure 1. Model of ionospheric waveguide excitation [4]

There is another model of electromagnetic wave scattering on such irregularities [6, 7]. In the model, the scattering character is determined by irregularity dimensions and the frequency of an electromagnetic wave falling on it. Under large values of the ratio of irregularity length to the wave length, we have cone scattering, under small values, the scattering is perpendicular to irregularity axis.

In October 2019 the information about EISCAT stand experiments in Norway became known. In order to observe them we used SDR «Kiwi» receiver network which is within the line of sight of the ionospheric impact area. As long as the network belongs to radio amateurs, we checked its usability for our observations applying Moscow precise time transmitter. Some of the receivers did not suite in stability, others had too high amplification constant.

To estimate magnetically-oriented irregularity parameters, the dependences of directional radiation patterns on irregularity dimensions, distances between them along and across the Earth's magnetic field were used [8]. Based on the results of measurements at two sites, we can determine the signal level ratio which for the given observation angles allows us to determine, for example, the ratio of irregularity length to the wave length. Heating emission frequency is known, it allows us to calculate, for example, irregularity longitudinal dimensions. 


\section{Observation results}

On October 18, received signal intensity changed stepwise, that indicated the fact that heating wave power on the heating stand changed. The step pattern manifested clearly during the time interval from 13.00 to 13.35 of universal time. Having processed the data and taking the maximum value as $100 \%$, we obtained relative change of impact power. Consequently, there is an opportunity to estimate the dependence of scattered signal properties and magnetically-oriented irregularity topology on the intensity of active impact on the ionosphere. To estimate fading, we used the ratios of dispersion to an average. For the comparison, data from two observation sites were applied. Processing results are illustrated in (Fig.2).

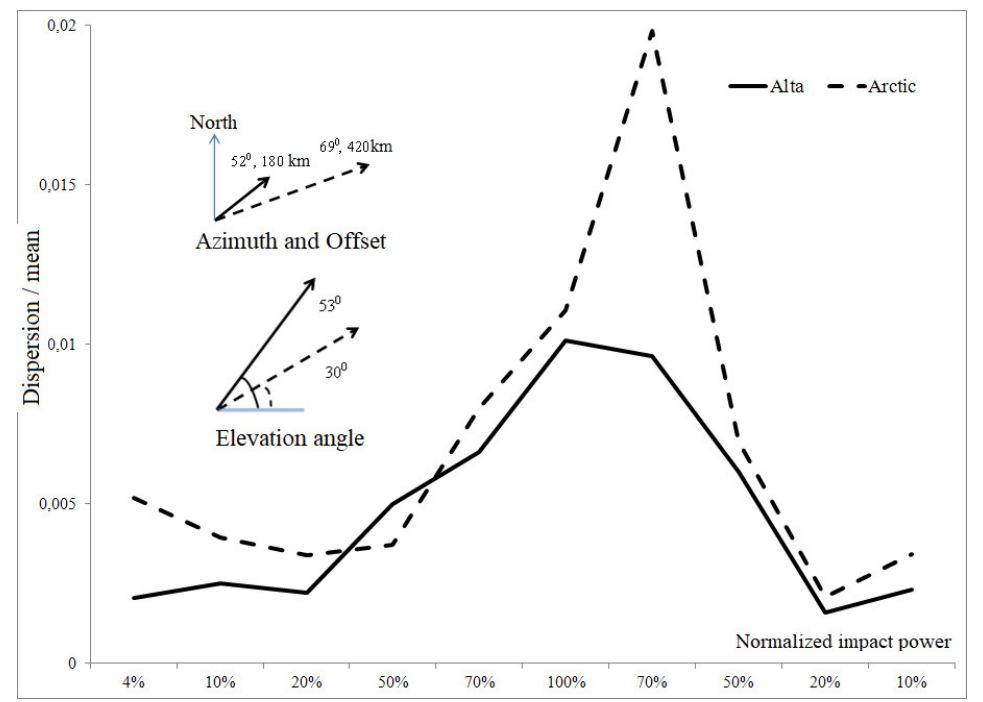

Figure 2. Distribution of scattered wave fading

The left part of the figure shows the offset, azimuth and angle of the irregularity formed over Tromse for two observation sites. It is obvious that these parameters differ. Nevertheless, correlation coefficient for two sites is quite high, 0,85. At the same time, function maxima and values do not coincide that may indicate different topology of irregularity regions where a scattered wave recorded at these sites is formed. As long as a scattered wave undergoes fading, it is logical to use not instantaneous values but amplitude distributions when determining irregularity topology. Processing results for Alta site are illustrated in (Fig.3). It is clear from the figure that the distribution has polymodal character, i.e. scattered wave intensity has several maxima. When impact power increases, both scatted component amplitude and its distribution law change. We use amplitudes with the largest number of counts to determine magnetically-oriented irregularity parameters. Based on the data obtained during the observations, we calculated longitudinal dimensions of magnetically-oriented irregularity, the distance between them along and across the Earth's magnetic field (Fig.4), (Fig.5), (Fig.6).

It follows from the analysis of magnetically-oriented irregularity topology that impact power affects the distance between irregularities along the Earth's magnetic field line the most. It is clear that for impact $100 \%$ power, irregularity configuration is similar to the periodic structure. Irregularity longitudinal dimensions depend on impact power to a less extent, though there is some tendency to structuring. The dependence on impact intensity is not observed in the variations of distances across the Earth's magnetic field line. We should note that within the period from 13.00 to 13.35 UT on 


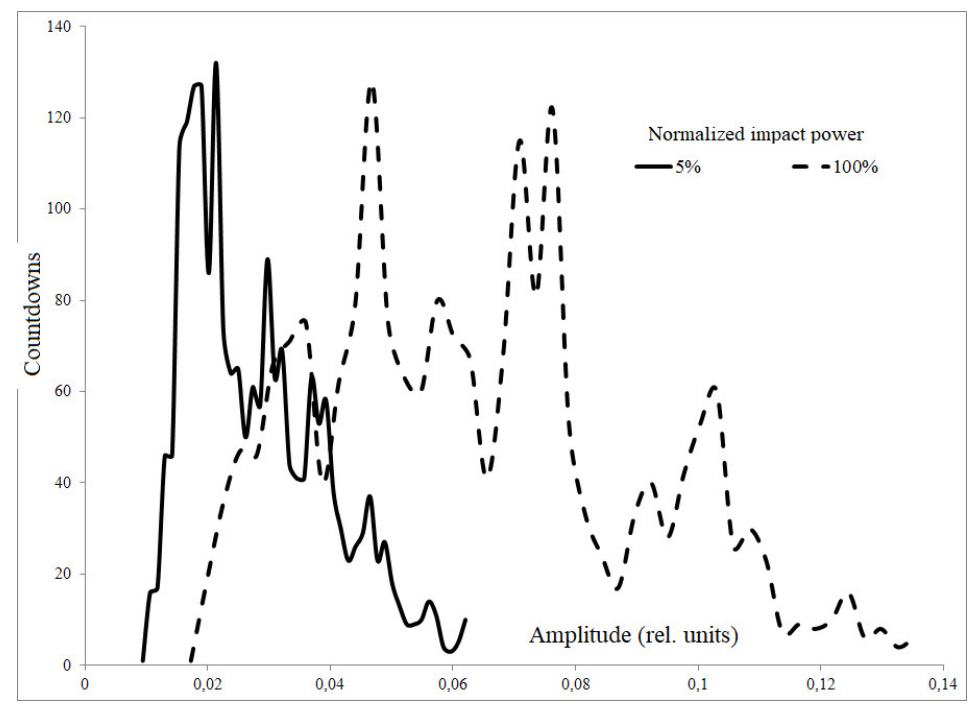

Figure 3. Amplitude distribution for different impact powers

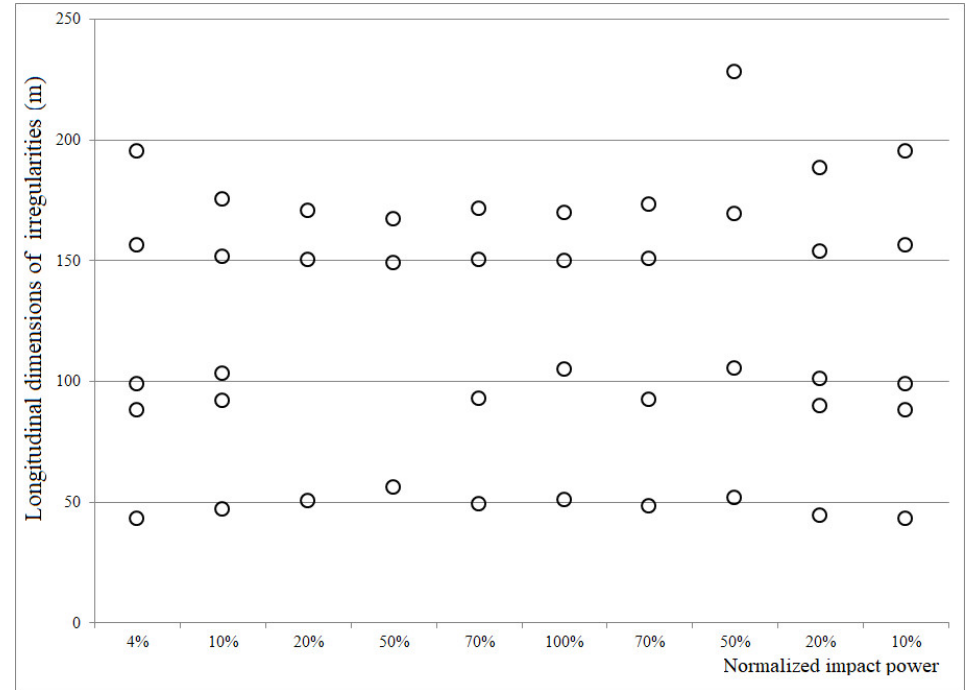

Figure 4. Longitudinal dimensions of magnetically-oriented irregularitis

October 18, 2019, heating wave frequency was $4544 \mathrm{kHz}$. It was found that this frequency is not a harmonic of hyro-magnetic frequency. We can assume that it is a hybrid one and the impact region is sufficiently extensive in altitude in this case [9]. Thus, to excite an ionospheric waveguide, such a choice of frequency is hardly suitable since, based on our observations, a scattered wave undergoes significant fading. 


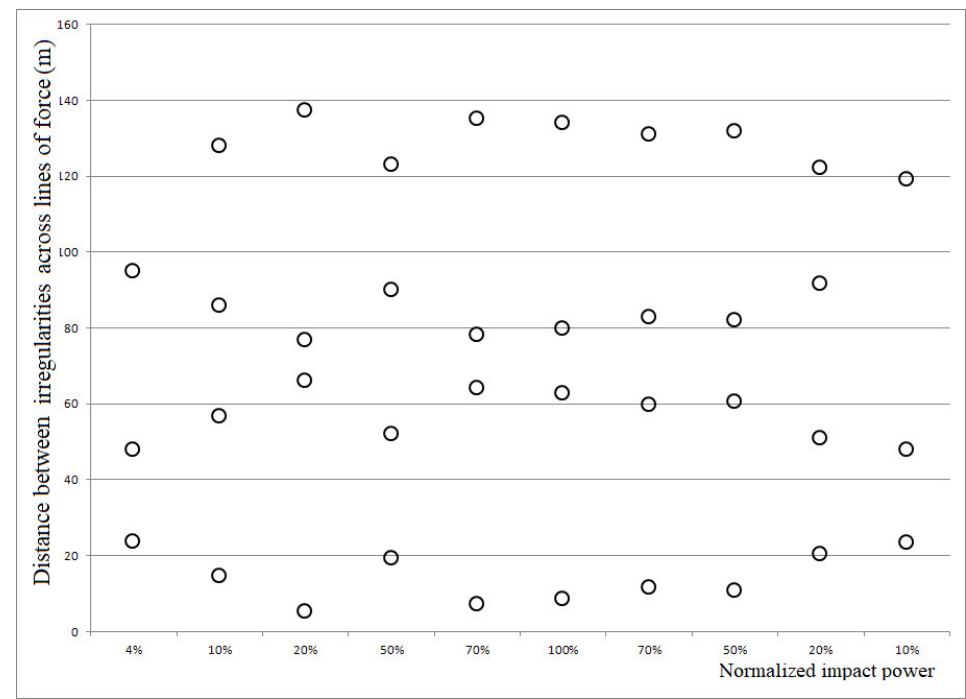

Figure 5. Distance between irregularities along a force line

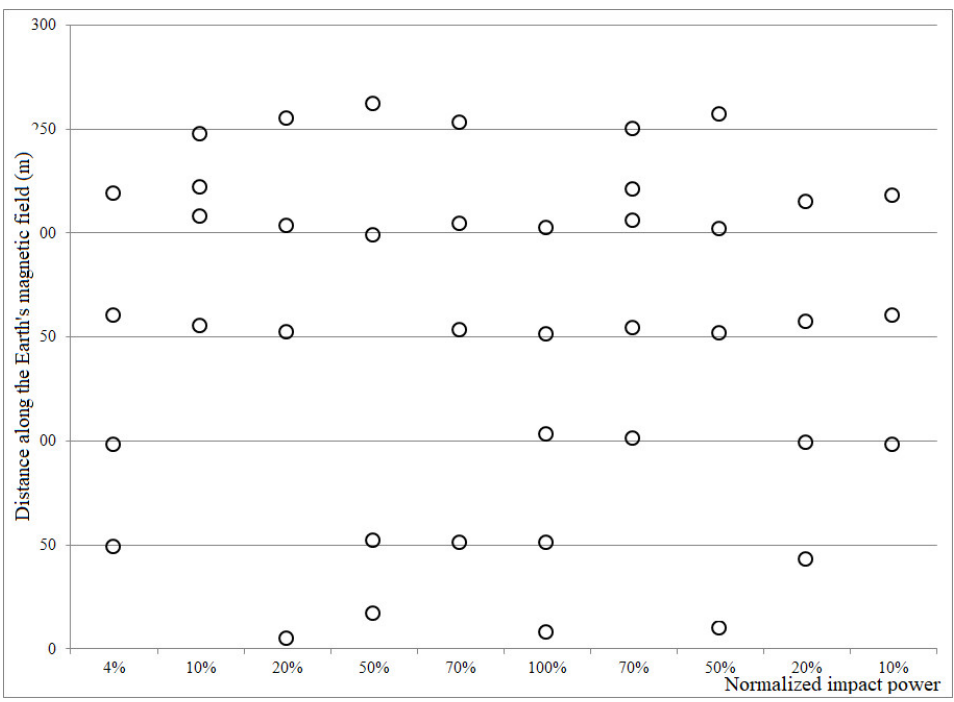

Figure 6. Distance across a field lin

\section{Conclusions}

Distribution of amplitudes and fading of the radiation scattered on ionospheric magnetically-oriented irregularities depends on impact power.

This dependence is explained, to some extent, by irregularity topology change but, to a large degree, it is likely to be explained by their motion. 
To create a trans-ionospheric channel of information transfer, it is reasonable to use the approach developed by the researchers from USA and Kharkov. In this case, information transfer should be organized on the frequencies adapted to magnetically-oriented irregularity topology.

\section{References}

[1] V. F. Bryantsev, Sposob transekvatorial'noy radiosvyazi v DKMV diapazone [A method of transequatorial radio communication in HF rang], RF Patent No. 2006127989/09, 01.08.2006. (in Russian)

[2] V. P. Uryadov, Sposob upravleniya rasprostraneniem korotkikh radiovoln v ionosfernom volnovode [A method to control short radio wave propagation in ionospheric waveguide], RF Patent No. 2009129810/09, 03.08.2009. (in Russian)

[3] Patent USA 9423495 SHIP-BASED OVER-THE-HORIZON RADAR, 2016

[4] Yampolski and e.t.c. Ionospheric Non-linear Effects Observed during Very-Long-Distance HF Propagation, Front. Astron. Space Sci. (2019) https://doi.org/10.3389/fspas.2019.00012

[5] V.P. Sivokon', I.M. Voroshilov, A.E. Masharova, E.V. Matanskaya Geofizicheskiy faktor effektivnosti vozdeystviya na ionosferu [Geoophysical factor of the efficiency of impact on the ionosphere], Vestnik Kamchatskogo gosudarstvennogo tekhnicheskogo universiteta - Bulletin of Kamchatka State Technical University, 43, 30-36 (2018) (in Russian)

[6] V.P. Sivokon', Magnitoorientirovannye neodnorodnosti - ionosfernaya sistema pereizluchateley [Magnetically-oriented irregularities, ionospheric system of reradiators], Izvestiya vysshikh uchebnykh zavedenii. Fizika, 59, No. 12-3, 56-60 (2016) (in Russian)

[7] V.P. Sivokon, Geomagnetism and Aeronomy, 57(3), 317-325 (2017) DOI: 10.1134/S001679321702013X

[8] V.P. Sivokon', R.V. Kolesnikov, I.V. Demichev Metod otsenki parametrov iskusstvennykh magnitoorientirovannykh neodnorodnostey ionosfery [Method to estimate the parameters of ionospheric artificial magnetically-oriented irregularities], Elektromagnitnye volny i elektronnye sistemy Journal of Electromagnetic Waves and Electronic Systems, 24, No. 8, 23-28, (2019) (in Russian)

[9] N.F. Blagoveshchenskaya, T.D. Borisova, A.S. Kalishin, T.K. Yeoman, Artificial Small-scale Field-aligned Irregularities in the High Latitude Ionospheric F-region, AGU FallMeeting $10-14$ December, 2018, Washington, DC, USA 